\title{
Effects of salinity on the survival, growth rate, and reproductive output of Gammarus lawrencianus (Crustacea, Amphipoda)
}

\author{
D. H. Steele, V. J. Steele \\ Dept of Biology, Memorial University of Newfoundland, St. John's, Newfoundland, Canada A1B 3X9
}

\begin{abstract}
Gammarus lawrencianus is classed as a genuine brackish-water species on the basis of the survival of juveniles, developing eggs and of reproducing adult females. This is consistent with its estuarine distribution in the northwestern Atlantic. At low salinities G. lawrencianus produced larger and fewer eggs but a total brood volume equivalent to that produced at higher salinities. Young hatched from the larger eggs at low salinities equalled in length those hatched from smaller eggs produced at higher salinities.
\end{abstract}

\section{INTRODUCTION}

Salinity is an important environmental variable for estuarine organisms and its many important physiological and ecological effects have been reviewed by Kinne $(1964,1966,1971)$. Most studies of crustaceans have dealt with the mechanisms by which adults adapt to varying salinities (Dorgelo 1976). According to Gilles \& Pequeux (1983) relatively few studies have been made of the effects of salinity on reproduction and embryonic development, although in amphipods such studies have been made for Gammarus duebeni by Kinne (1959), for Echinogammarus marinus by Vlasblom \& Bolier (1971) and for Corophium spp. by Shyamasundari (1976) and Mills \& Fish (1980).

These studies have generally shown that the number of eggs per brood, the viability of the developing embryos and the growth rate of the young are maximal at an intermediate salinity characteristic for the species. Adults can tolerate a wider range of salinities but may not be able to reproduce at low salinities. However, there is little information available on possible effects of salinity on eggs and total reproductive output in any species, although Hynes (1954) reported that the eggs of Gammarus duebeni from fresh water were larger than those from brackish water.

Gammarus lawrencianus Bousfield is a small estuarine amphipod of the northwestern Atlantic (Steele \&
Steele 1974) which is easily cultured in the laboratory. Previous studies have considered its life cycle in the field (Steele \& Steele 1970) and its life history tactics when compared to other Gammarus species (Steele \& Steele 1975). Its survival, growth and reproduction vary with diet (Vassallo \& Steele 1980, Steele 1982) and photoperiod (V. J. Steele 1981, V. J. Steele \& Steele 1986) when cultured in the laboratory.

The purpose of the present study was to determine if salinity variations influenced the growth rates and reproductive outputs (egg sizes and numbers of eggs per brood). However, it was first necessary to determine how salinity affected the survival of young and of reproducing females, since this had not yet been determined for this species.

\section{MATERIALS AND METHODS}

Three separate experiments are described and discussed here. Expt 1 in spring 1985 determined growth and survival rates to maturity and reproductive output of maturing females raised at different salinities.

Adults collected in the small estuary at Witless Bay, on the east coast of the Avalon Peninsula, Newfoundland, Canada $\left(47^{\circ} 16^{\prime} \mathrm{N}, 52^{\circ} 49^{\prime} \mathrm{W}\right)$ were maintained in a container of seawater (salinity $30 \%$ ). Newly hatched young were pooled in a large container. Groups of 25 
young were placed in small containers and maintained at $20^{\circ} \mathrm{C}$ under 18L: $6 \mathrm{D}$ photoperiods. Freeze-dried alga Pilayella littoralis, collected on the open coast at Witless Bay, was provided in excess as food.

The small containers contained water of different salinities, prepared by diluting filtered seawater with distilled water. The salinities used were $0,2.5,5,10$, 15,25 and $30 \%$. At least 2 replicates of each salinity were used.

Cultures were examined every $3 \mathrm{~d}$ until mating pairs were anticipated, at which time observations were made every morning. Mating normally occurs at night and the ovigerous females were removed and preserved the following morning. The length of the extended female parent was measured from the anterior tip of the head to the end of the telson. The eggs were removed from the brood pouch, counted and their length and width measured. Mean diameter of an egg was calculated as (length + width) $/ 2$ and the volume of an egg as a prolate spheroid: $4 / 3 \pi$ length $/ 2$ $x(\text { width } / 2)^{2}$ Brood volume was determined as the mean volume of the eggs in a brood $x$ their number. Amphipods were counted every 7 to $8 \mathrm{~d}$.

Expt 2 in spring 1989 examined the duration of embryonic development, survival of developing embryos and the sizes of newly hatched young at different salinities. Observations of growth, survival and reproductive output of the maturing females were also recorded.

This experiment was similar to the first except that only salinities of 5,15 and $35 \%$ were tested. Four containers of 25 amphipods were established at each salinity. Specimens in 2 containers at each salinity were processed as in the first experiment when the females matured and produced their broods. Specimens in the other 2 containers were maintained until their eggs hatched. The newly hatched young were counted and measured.

Expt 3 compared the survival rates of breeding and non-breeding adult females at different salinities. The females were induced to enter or leave ovarian diapause by exposure to photoperiods at different salinities. Adult females were established in cultures in June 1980. On July 20, groups of 30 females plus a few males were placed in small containers. One half of these containers had water with $30 \%$ salinity and the other half $10 \%$. Excess food in the form of freeze-dried Pilayella littoralis was provided.

Breeding status of the females was determined by the presence (breeding) or absence (non-breeding) of setae on their oostegites. The number of females in each category and the total number of surviving females was determined after $62,102,178$ and $240 \mathrm{~d}$.

The statistical significance of the differences between the means of size and age at maturity, growth rate to maturity and egg diameter was determined by analysis of variance (ANOVA) and Newman-Keuls (SNK) multiple range tests. Although excess food was provided in each container the intra-unit correlations were negative, suggesting that there may have been competition for food and thus that there is a risk of a type II error. Therefore the individual observations were used when testing for statistical significance (Hairston 1989). The number of eggs was regressed on length of the parent in grand mean regressions using power curves. The volume of the broods was similarly regressed on length (equivalent to volume of the parent), also in grand mean regressions using power curves. The regression lines were compared using analysis of covariance (ANCOVA). Correlations were determined with the product moment correlation coefficient. In all cases the accepted level of significance is 0.05 .

\section{RESULTS}

\section{Survival of immature females}

Since mortality is greater in breeding females than it is in non-breeding females (V. J. Steele \& Steele 1986), survival is only comparable until the females mature and commence breeding. As reproduction began after varying intervals at the different salinities, survival is shown for varying time periods in Fig. 1. Females placed in distilled water survived for a few days but all died before reproducing. Those in $2.5 \%$ suffered a $64 \%$ mortality in the first $8 \mathrm{~d}$ but the survivors were much more tolerant of this low salinity and there was only a $23 \%$ mortality during the next $42 \mathrm{~d}$, at which time they commenced breeding

When compared for a standard time period of $21 \mathrm{~d}$, which is before breeding began at any salinity, the highest survival occurred between 15 and $20 \%$ (Fig. 2). The low salinity $\mathrm{LC}_{50}$ for $21 \mathrm{~d}$ is calculated by probit analysis to be $6.1 \%$. Survival times increased with salinity (Fig. 1). However, after 21 d when some started breeding, the change in $\mathrm{LC}_{50}$ over time becomes confounded with increased mortality due to reproduction.

Survival was almost identical at $5 \%$ and $15 \%$ in Expts 1 and 2 (Fig. 2). However, survival was higher at $35 \%$ in Expt 2 that it was at $30 \%$ in Expt 1. Inspection of Fig. 1 shows that the reduced survival at $30 \%$ was due to a high mortality in the first week of the experiment even though the salinity was the same as that in which the amphipods had previously been held. After the first week in the small containers survival at $30 \%$ was similar to that observed at $35 \%$. Thus the survival rate plotted at $30 \%$ in Fig. 2 is undoubtedly too low. 


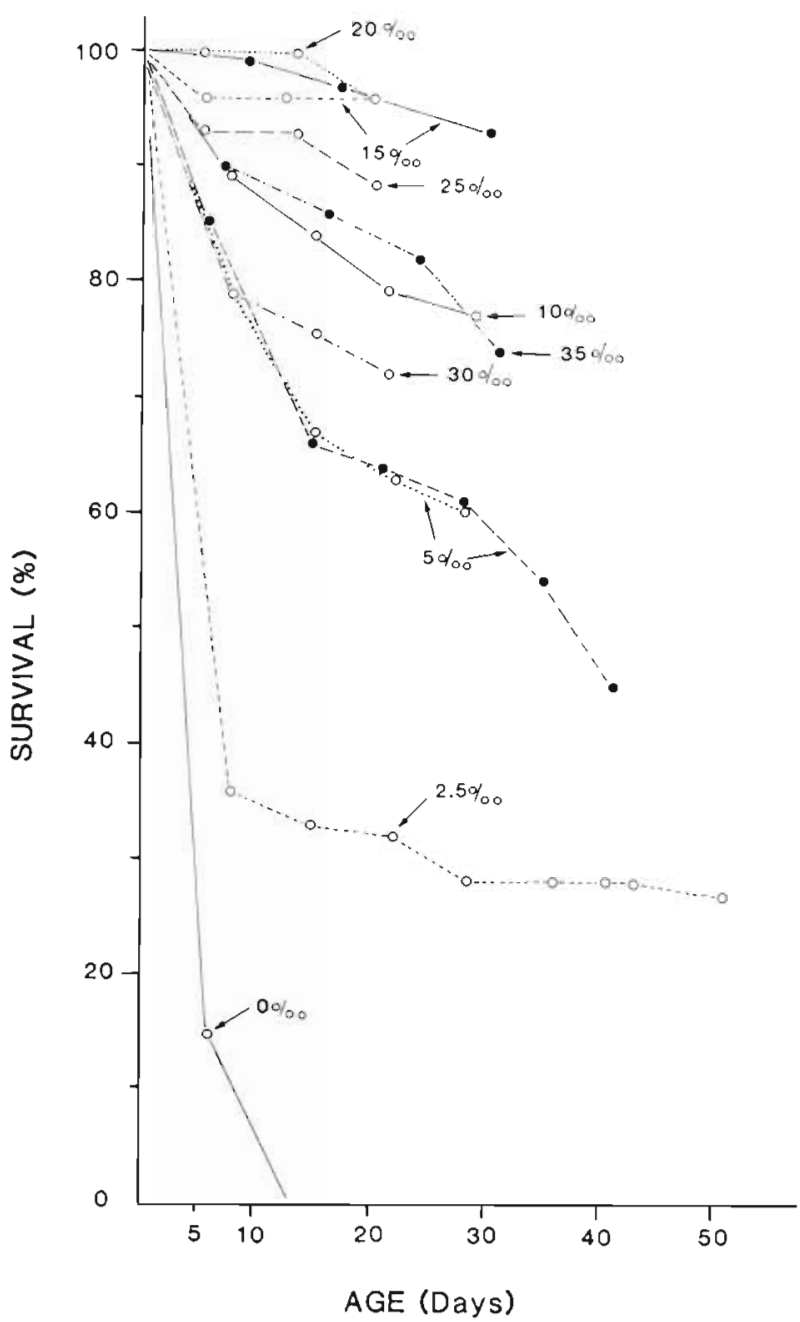

Fig. 1 Gammarus lawrenclanus. Survival rates (\%) of immatures at various salinities

\section{Reproduction and survival of adults at $\mathbf{1 0} \%$ and $30 \%$ salinities under varying photoperiods}

Salinity had no apparent effect on either the induction or termination of ovarian diapause. The mortality of breeding females was much lower at $30 \%$ than at $10 \%$ (Fig. 3) and was correlated with the percentage breeding $(r=0.96, p<0.01)$. At $10 \%$, mortality was high and varied only slightly with the percentage breeding.

\section{Growth rate and size and age at maturity}

Expt 1. Growth rate to maturity (Fig. 4) did not differ significantly between 15 and 30\% (ANOVA, p > 0.05), but declined progressively at salinities from $10 \%$ to $2.5 \%$ (SNK, p < 0.05).

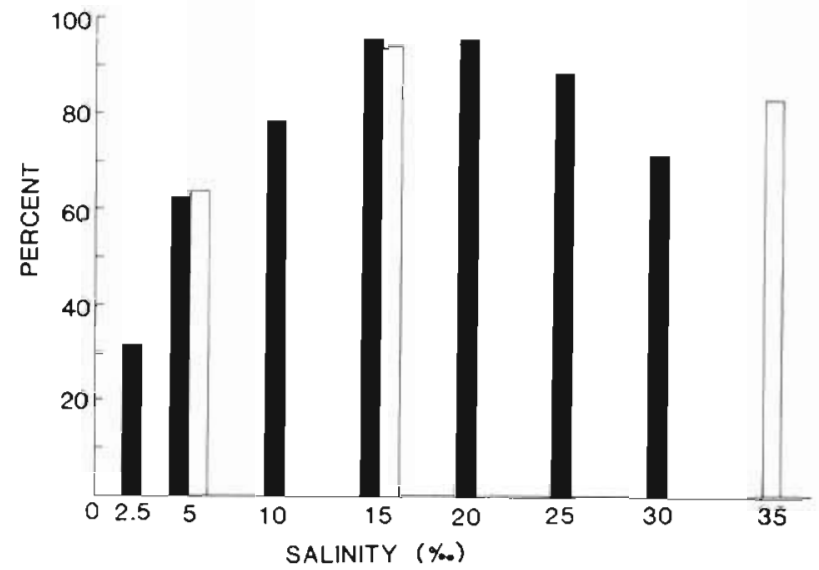

Fig. 2. Gammarus lawrencianus. Survival rates (\%) of immatures for a period of $21 \mathrm{~d}$ at various salinities. Solid bars: Expt 1; open bars: Expt 2

Length at maturity (Fig. 5) did not differ significantly between 5 and 25\% (ANOVA, p > 0.05). Those maintained at $2.5 \%$ were significantly longer and those at $30 \%$ were significantly smaller than those raised at the intermediate salinities (SNK, $\mathrm{p}<0.05$ ). However, lengths observed at $30 \%$ are suspect due to a higher than expected mortality (see below) at this salinity and since the size at maturity of females at $35 \%$ in the second experiment was large (see below).

Age at maturity (Fig. 6) varied inversely with the growth rates and females at $2.5 \%$ salinity took longest to reach maturity. The relationship between growth rate and age at maturity is non-linear and similar to that observed when diet was varied (Fig. 6; Steele 1982).

Expt 2. Growth rates to maturity (Fig. 4), age at maturity and size at maturity (Fig. 5) did not differ significantly at 15 and $35 \%$. At $5 \%$ growth rate to maturity was significantly less, age at maturity greater and size at maturity smaller than at the

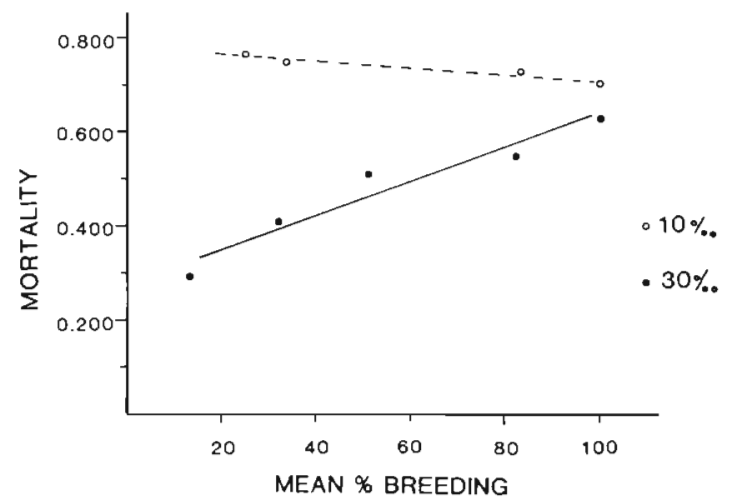

Fig. 3. Gammarus lawrencianus. Mortality rates of females related to percentage breeding at $10 \%$ and $30 \%$ salinity. Breeding was induced or terminated by varying photoperiods 

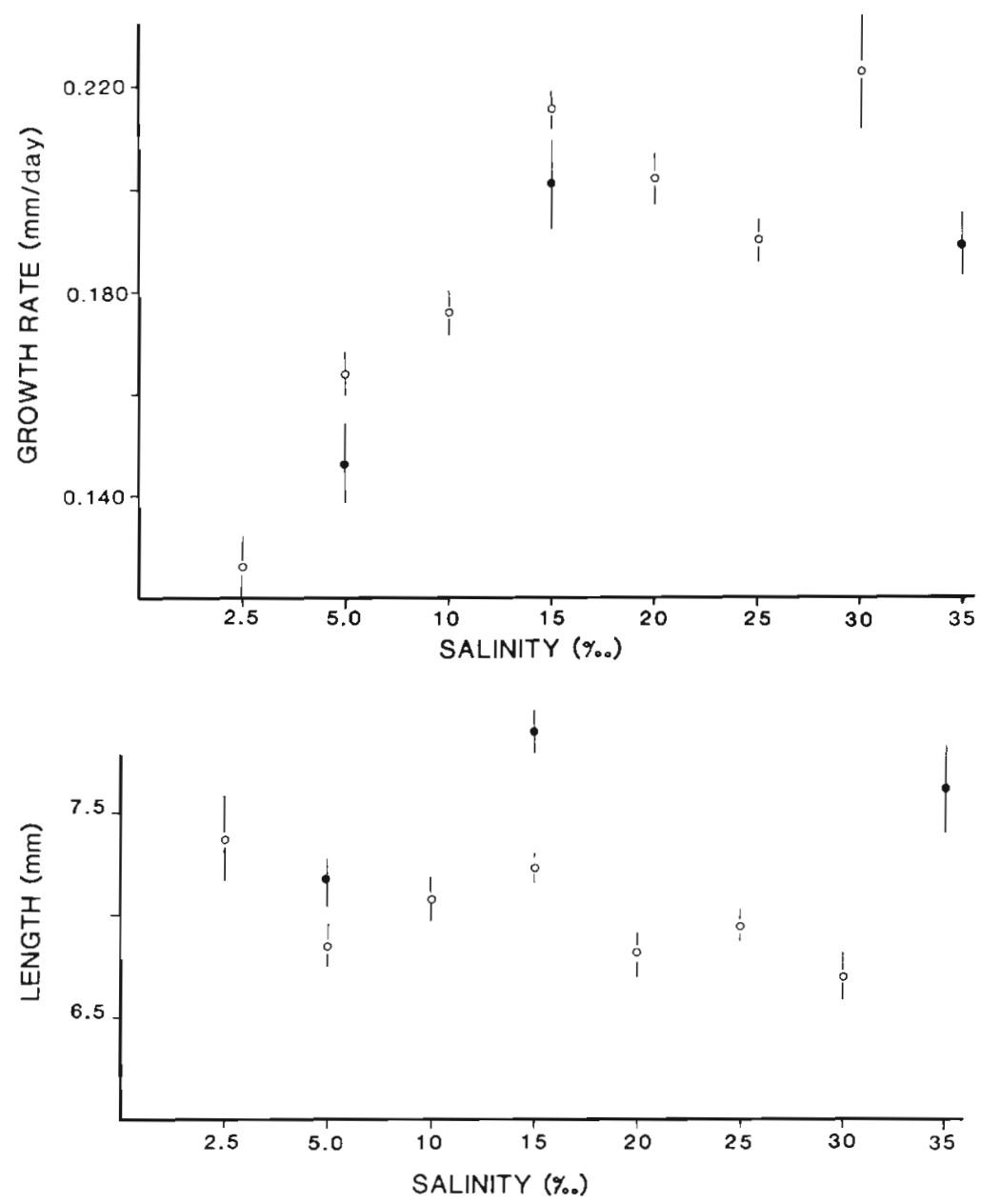

Fig. 4. Gammarus lawrencianus. Growth rates (mean $\pm \mathrm{SE}$ ) of females maintained at various salinities. (0) Expt $1_{i}(\bullet)$ Expt 2 other salinities. This trend is similar to what was found in Expt 1. However, the absolute values obtained in Expt 2 all differed significantly from those obtained in Expt 1 at the same salinity. The reason for these differences is unknown, but it may have been related to differences in the quality of the pilayella littoralis used as food in the 2 experiments.

\section{Reproductive output}

Expt 1. Mean egg diameter (Fig. 7) was greatest at $2.5 \%$ and decreased as salinities increased up to $15 \%$. Egg size did not differ significantly at salinities between 15 and $30 \%$.

The number of eggs varied directly with body length (Fig. 8A). It was significantly less (ANCOVA, $p<0.05$ ) at a salinity of $2.5 \%$ than at the higher salinities. At $5 \%$, brood size was also lower than at the higher salinities but the difference is not significant (ANOVA, p > 0.05). Since two-thirds of the maturing females at $30 \%$ were $7 \mathrm{~mm}$ in length, it was not possible to calculate a regression with a reasonable slope at this salinity. However, the mean number of eggs produced by the $7 \mathrm{~mm}$ females did not differ significantly from the numbers produced by females of the same size at salinities between 5 and $25 \%$. (ANOVA, p > 0.05).

The interaction between numbers of eggs produced and their volumes is such that the total volume of the broods show no consistent variation with salinity between 2.5 and 25\% (Fig. 9). Thus the smaller numbers of eggs produced at $2.5 \%$ was compensated for by their larger size so that the brood volume was comparable to that of the other saliniities. However, at any particular salinity, the sizes of the eggs are not correlated with the number of eggs in the broods produced by individual females $(r=0.1, p>0.05)$.

Expt 2. Similar trends in reproductive output were found in this experiment although the actual values differed from those in the first experiment. Mean egg diameters were larger and varied from $0.470 \mathrm{~mm}$ at $5 \%$ to $0.407 \mathrm{~mm}$ at $35 \%$. The sizes of the broods did not vary significantly with salinity (Fig. $8 \mathrm{~B}$ ) but were significantly less than in Expt 1. Brood volume also did not vary with salinity. The interaction between egg volume and numbers at each salinity resulted in brood volumes that did not differ between the 2 


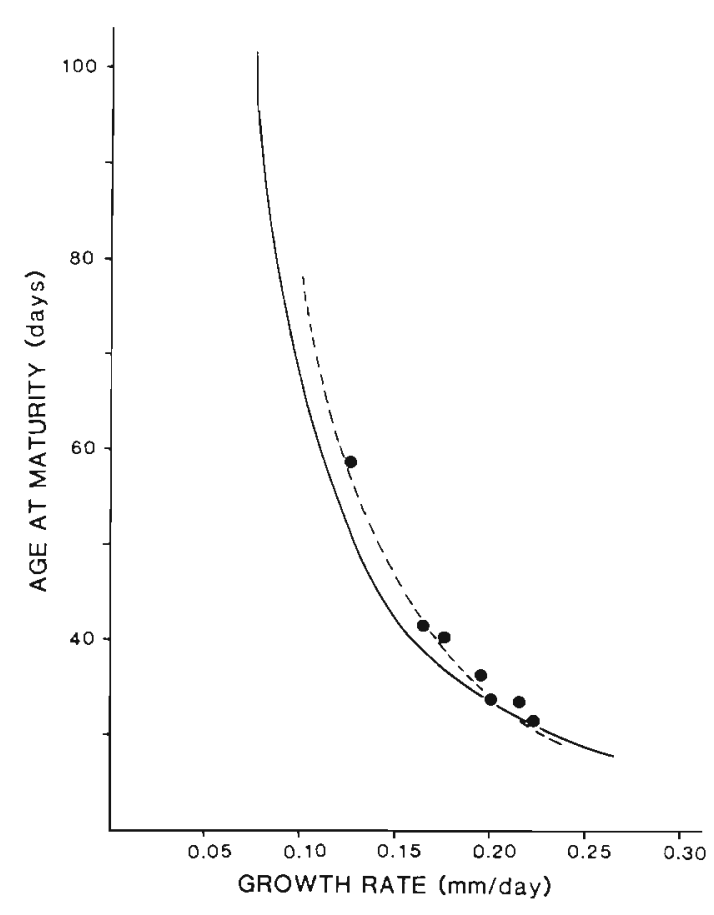

Fig. 6. Gammarus lawrencianus. Age at maturity of females related to growth rate. $(\bullet-\cdots)$ |Fitted line: Age $=8.046$ (Growth Rate -0.050$)^{-0761}$ ) obtained from the various salinities. $(-) \mid$ Age $\left.=11.079(\text { Growth Rate }-0.050)^{-0.605}\right)$ obtained with diet as the variable (Steele 1982)

experiments at $15 \%$. However, brood volumes were smaller in Expt 2 at $5 \%$.

Embryonic development was of the same duration at 15 and $35 \%$. Hatching success of the embryos varied with salinity. No embryos hatched at $5 \%$. At $15 \%$, only $57 \%$ of the broods hatched, and of those that did, the numbers of young did not differ from the number of embryos (Fig. 10). All broods hatched at $35 \%$, but there were significant decreases in their sizes.

\section{DISCUSSION}

Salinity as an environmental factor has been considered mostly in terms of its effects on survival and distribution, and only to a much lesser extent as an environmental parameter affecting the reproductive strategies of marine animals. Both aspects are discussed here for Gammarus lawrencianus.

Dorgelo (1976) suggested that crustaceans could be divided into 5 groups on the basis of their salt tolerance. Gammarus lawrencianus would be considered as a 'more or less euryhaline genuine brackishwater species' (Type IV) since maximum survival to maturity occurred at salinities of 15 to $20 \%$. However, individual females survived and produced eggs at higher and lower salinities.

These experimental results are consistent with the distribution of this species (Steele \& Steele 1970). Gammarus lawrencianus is normally found in estuaries and not on the open coast at high salinities $(30+\%)$. The only exceptions are during periods of heavy freshwater runoff, such as the period of snow melt in the spring or after a heavy rainstorm. At these times specimens of $G$. lawrencinaus may be found on open coasts if near an estuary. G. lawrencianus may also be found localized at about midtide level on coarse sedimentary shores if there is freshwater seepage (Steele 1983).

Within estuaries, Gammarus lawrencianus is potentially exposed to varying salinities, rather than
Fig. 7 Gammarus lawrencianus. Egg diameters (mean \pm SE) at various salinities. (0) Expt $1 ;(\bullet)$ Expt 2

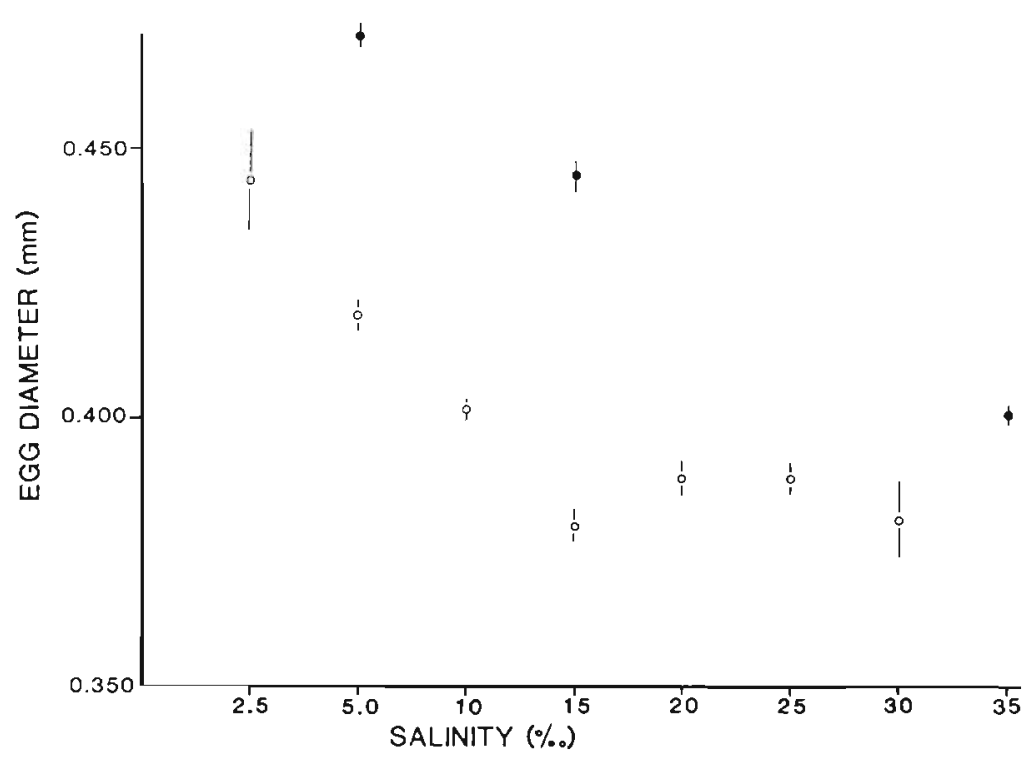




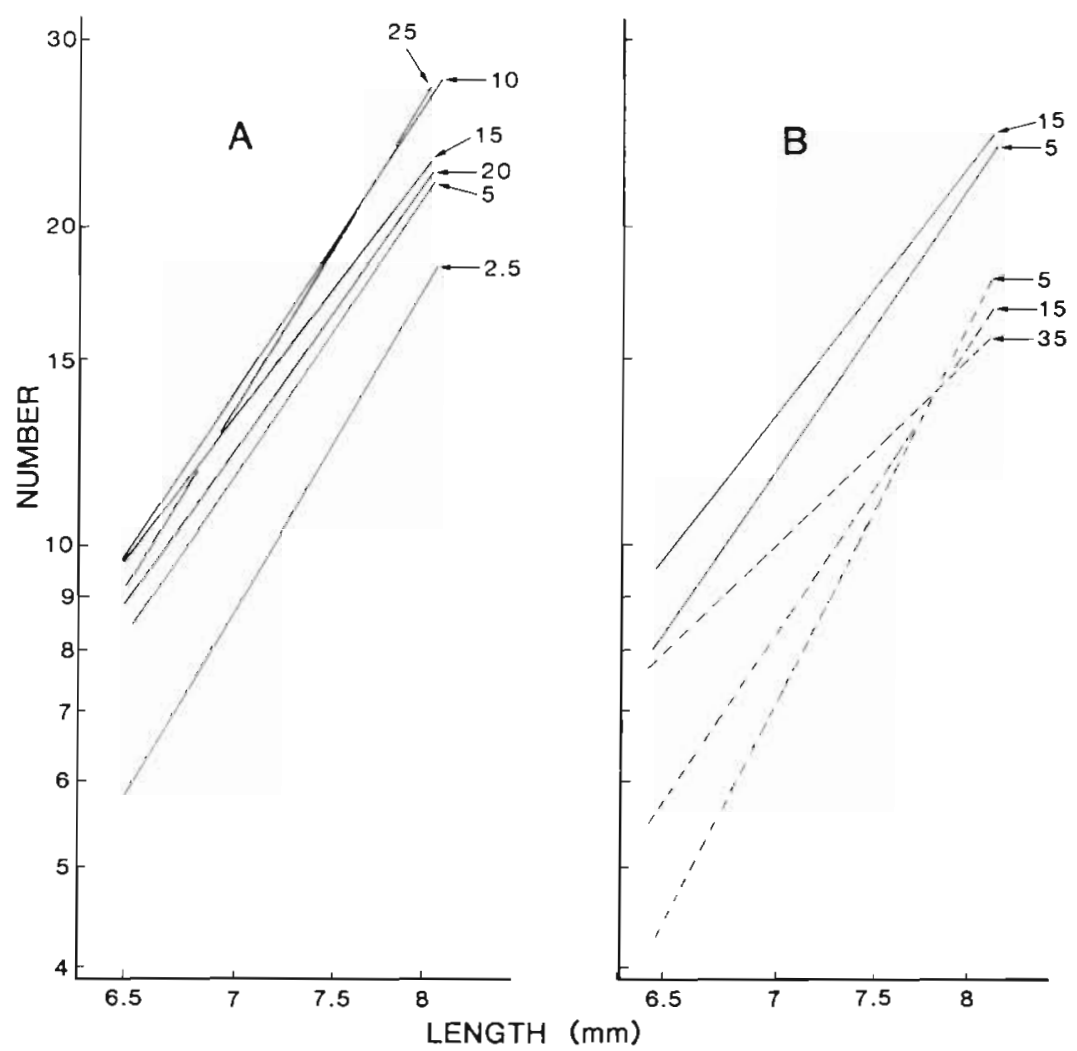

Fig. 8. Gammarus lawrencianus. Grand mean regressions of numbers of eggs related to female body length at various salinities. (A) Expt $1_{i}$ (B) (-) Expt 1; $(--)$ Expt 2

the constant salinities used in the present experiments. However, individuals can and do avoid extreme fluctuations by moving horizontally and/or vertically. During freshets they move further out-

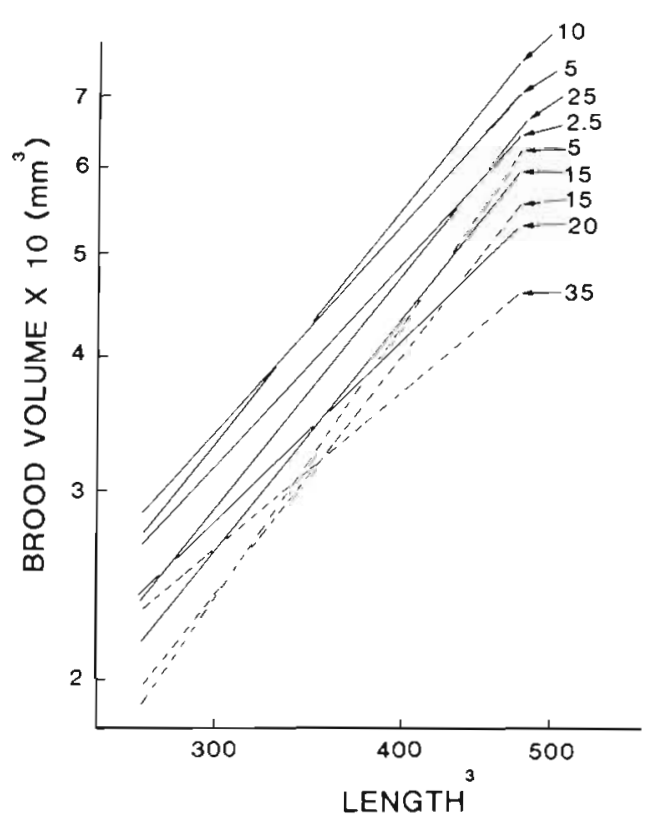

Fig. 9. Gammarus lawrencianus. Grand mean regressions of brood volumes related to cube of body length at various salinities. (A) Expt $1 ;(B)(-)$ Expt $1 ;(--)$ Expt 2 wards or downwards. In the 2-layered estuaries typical of eastern Newfoundland they are found in the saline water below the surface layer of fresh water or under rocks where the residual water

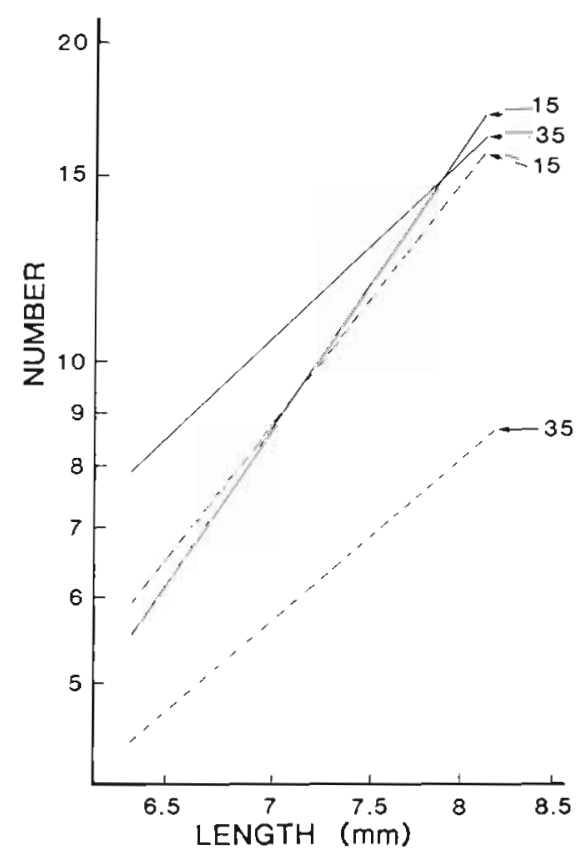

Fig. 10. Gammarus lawrencianus. Grand mean regressions of the numbers of eggs (-) and numbers of hatched young $(--)$ against female body length at 15 and $35 \%$ 
remains saline even during low tides. The only individuals to survive the winter are found at the bottom of the 2-layered estuaries.

In New Brunswick, where Gammarus lawrencianus and its near relative $G$. tigrinus coexist in estuaries, $G$. lawrencianus occurs seaward of the latter species, although there is some overlap (Steele 1983). Dorgelo (1976) classed $G$. tigrinus as an 'extremely euryhaline species that tolerates the entire range from marine to limnetic conditions equally well' (Type III). However, the experimental results (Dorgelo 1974) indicate that the highest survival of adults was at salinities between 1 and $17 \%$ with higher mortalities at the higher and lower salinities. This would place $G$. tigrinus in Type IV with $G$. lawrencianus and its maximum survival at 1 to $17 \%$ is consistent with its estuarine distribution in both North America and Europe.

The higher mortalities of breeding females and of developing eggs at low salinities show that the salinity tolerances for reproduction are reduced. Reduced viability at low salinities has also been reported in Corophium spp. by Shyamasundari (1976) and Mills \& Fish (1980). Vlasblom \& Bolier (1971) likewise found a reduced viability in the eggs of Echinogammarus marinus at low salinities and concluded that the egg membrane offered 'only weak protection to the embryos' so that the extra-embryonic fluid of the eggs becomes isotonic in a short time. Thus at low salinities the eggs swell by imbibing water due to osmosis.

Within its estuarine habitat, Gammarus lawrencianus undergoes marked seasonal fluctuations in abundance. In the winter females have an ovarian diapause, reproduction stops and the population declines. However, the multivoltine (small size at maturity, short embryonic development period) and iteroparous life cycle results in the attainment of a high population density by late summer (Steele \& Steele 1970).

The present study shows that growth and survival of the young are maximal at the intermediate salinities where the population is normally found in nature. This is similar to what has been observed in another estuarine species, Gammarus duebeni, by Kinne (1959). However, the optimal salinities for growth are higher $(15+\%)$ for G. lawrencianus than for G. duebeni ( 5 to $20 \%$ ) and, where they occur together, G. duebeni is found landward of both $G$. lawrencianus and $G$. tigrinus (Steele 1983).

Kinne $(1959,1971)$ observed that the final body length in Gammarus duebeni was greatest at a salinity of $10 \%$ with lower values at both higher and lower salinities. In $G$. lawrencianus the size at maturity was variable but did not vary consistently with salinity.

The relationship between growth and the age at maturity observed with different salinities is similar to that found when diet influences the growth rate; when growth is reduced by low salinity the age at maturity increases. However, the effect is not uniform over the range of growth rates. Although very low growth rates were not achieved with salinity as the variable, at salinities of less than $2.5 \%$ growth would be so slow that maturity would not be reached in the normal life span.

Egg size increased at salinities less than $15 \%$, so that eggs at 2.5 and $5 \%$ salinity in Expt 1 and at 5 and $15 \%$ in Expt 2 exceeded the mean size $(0.409 \mathrm{~mm})$ of eggs measured in field collections (Steele \& Steele 1970).

The large eggs produced in Expt 2 at 5 and $15 \%$ salinities had reduced viabilities. The young hatched from the large eggs at $15 \%$ took the same time to develop and were not significantly larger than those from the smaller eggs produced at $35 \%$.

The reduced fecundities at low salinities varied inversely with the larger size of the eggs such that the total brood volume was comparable to that at the higher salinities. This non-genetic effect was produced by exposure to low salinities and is probably due to the eggs imbibing water by osmosis, since the size of the newly hatched young did not increase. The swelling of the eggs reduced the number of eggs produced per brood, but the total volume of each brood remained constant. Moreover, the large eggs produced at the low salinities did not hatch. Thus, the production of eggs at the low salinities is not an indication of successful adaptation.

Geographic and seasonal variations in egg size have often been reported in amphipods, including Gammarus lawrencianus (e.g. Steele \& Steele 1970) and other crustaceans but they usually have been related to variations in water temperature rather than salinity. Mashiko (1990), however, reported variations in egg size in the prawn Macrobrachium nipponense that were related to habitat salinity. There was an inverse correlation between the salinity of the habitat and egg size. The number of eggs per brood was in turn inversely correlated with egg size but the total size of the brood measured as the ratio of the mass of the eggs to that of the female parent varied independently of the habitat. At some, but not all sites, large eggs compensated for a low number. This is similar to what was found here in the present experiments. However, the differences in $M$. nipponense are evidently genetic since young raised at different salinities 'laid eggs of unchangeable size'. In addition, larger zoea hatched from larger eggs and vice versa (Mashiko 1990).

Freshwater Gammarus species, in common with many other crustaceans, produce larger eggs than the marine Gammarus (Steele \& Steele in press). These differences in egg size must also be partly genetic, but the reasons remain obscure. 


\section{LITERATURE CITED}

Dorgelo, J (1974). Comparative ecophysiology of gammarids (Crustacea: Amphipoda) from marine, brackish and freshwater habitats, exposed to the influence of salinitytemperature combinations. 1. Effect on survival. Hydrobiol. Bull. 8: 90-108

Dorgelo, J. (1976). Salt tolerance in Crustacea and the influence of temperature upon it. Biol. Rev. 51: 255-290

Gilles, R., Pequeux, A. (1983). Interactions of chemical and osmotic regulation with the environment. In: Vernberg, F J., Vernberg, W. B. (eds.) Environmental adaptations. The biology of Crustacea, Vol. 8. Academic Press, New York, p. 109-177

Hairston, N. G. Sr (1989). Ecological experiments. Cambridge Univ. Press, New York

Hynes, H. B. N. (1954). The ecology of Gammarus duebeni Lilljeborg and its occurrence in fresh water in western Britain. J. Anim. Ecol. 23: 38-84

Kinne, O. (1959). Ecological data on the amphipod Gammarus duebeni. A monograph. Veröff. Inst. Meeresforsch. Bremerh. 6: 177-202

Kinne, O. (1964). The effects of temperature and salinity on marine and brackish water animals. II. Salinity and temperature-salinity combinations. Oceanogr. mar. biol. A. Rev. 2: $281-339$

Kinne, O. (1966). Physiological aspects of animal life in estuaries, with special reference to salinity. Neth. J. Sea Res. 3: 222-244

Kinne, O. (1971). Salinity: Animals: Invertebrates. In: Kinne, O. (ed.) Marine ecology, Vol. 1, Environmental factors, Part 2. Wiley-Interscience, Chichester, p. 821-995

Mashiko, K. (1990). Diversified egg and clutch sizes among local population of the fresh-water prawn Macrobrachium nipponense (de Haan). J. Crust. Biol. 10: 306-314

Mills, A., Fish, J. D. (1980). Effects of salinity and temperature on Corophium volutator and C arenarium (Crustacea Amphipoda), with particular reference to distribution. Mar. Biol. 58: 153-161

This article was submitted to the editor
Shyamasundari, K. (1976). Effects of salinity and temperature on the development of eggs in the tube building amphipod Corophium triaenonyx Stehbing. Biol. Bull. mar. biol. Lab., Woods Hole 150: 286-293

Steele, D. H. (1982). Survival, growth and reproduction of Gammarus lawrencianus on a diet of Pilayella littoralis. Pol. Arch. Hydrobiol. 29: 299-306

Steele, D. H. (1983). Coarse sedimentary shores. In: Thomas, M. L. H. (ed.) Marine and coastal systems of the Quoddy region, New Brunswick. Can. Spec. Pub. Fish. Aquat. Sci. No. 64, p. 74-94

Steele, D. H., Steele, V. J. (1970). The biology of Gammarus (Crustacea, Amphipoda) in the northwestern Atlantic. IV Gammarus lawrencianus Bousfield. Can. J. Zool. 48: $1261-1267$

Steele, D. H., Steele V. J (1974). The biology of Gammarus (Crustacea, Amphipoda) in the northwestern Atlantic VIIl. (ieographic distribution of the northern species. Can. J. Zool 52: 1115-1120

Steele, D. H., Steele, V. J. (1975). The biology of Gammarus (Crustacea, Amphipoda) in the northwestern Atlantic. XI. Comparison and discussion. Can. J. Zool. 53: $1116-1126$

Steele, D. H., Steele, V. J (in press). Morphological and environmental restraints on egg production in amphipods In: Wenner, A. (ed.) Crustacean egg production. A. A. Balkema, Rotterdam

Steele, V. J (1981). The effect of photoperiod on the reproductive cycle of Gammarus lawrencianus Bousfield. J exp. mar. Biol. Ecol. 53: 1-7

Steele, V. J., Steele D. H. (1986). The influence of photoperiod in the timing of reproductive cycles in Gammarus species (Crustacea, Amphipoda). Am. Zool. 26: 459-467

Vassallo, L., Steele, D. H. (1980). Survival and growth of young Gammarus lawrencianus Bousfield, 1956, on different diets. Crustaceana, Suppl. 6: 118-125

Vlasblom, A. G., Bolier, G. (1971). Tolerance of embryos of Marinogammarus marinus and Orchestia gammarella (Amphupoda) to lowered salinities. Neth. J. Sea Res. 5: $334-341$

Manuscript first recenved: March 22, 1991

Revised version accepted: October 9, 1991 